\title{
Mechanisms of cerebral artery thrombosis: a histopathological analysis on eight necropsy cases
}

\author{
Jun Ogata, Junichi Masuda, Chikao Yutani, Takenori Yamaguchi
}

\begin{abstract}
The mechanisms of thrombus formation in atherosclerotic cerebral arteries are still controversial, although intraplaque haemorrhage and rupture of the atheromatous plaques have been proposed. A histopathological analysis of segments of the thrombosed large intracranial arteries was carried out on eight patients who died within 28 days after brain infarction. The study revealed occlusive thrombi in six and mural thrombi in two, developing mostly at the site of greatest stenosis or just distal to it. The histological characteristics of the thrombosed arteries were plaque rupture in three, intramural haemorrhage in one, ulceration in one, and thrombosis in the absence of plaque rupture or intramural haemorrhage in three. Occlusive emboli distal to the site of cerebral artery thrombosis (intracranial artery-to-artery thromboembolism) were observed in two. The following conclusions were drawn from the study: 1) plaque rupture or intraplaque haemorrhage is not a sine qua non for cerebral artery thrombosis; 2) occlusions occur at the site of greatest luminal compromise or just distal to it, and 3) non-occlusive mural thrombosis can occur in the absence of plaque rupture and eventually lead to local occlusion or distal embolisation.
\end{abstract}

(F Neurol Neurosurg Psychiatry 1994;57:17-21)

Research Institute, National

Cardiovascular

Center, Osaka, Japan

J Ogata

J Masuda

Department of

Pathology

C Yutani

Cerebrovascular Division, Department of Medicine

T Yamaguchi

Correspondence to: Dr Ogata, National

Cardiovascular Center

Research Institute, 5-7-1,

Fujishirodai, Suita, Osaka,

Japan

Received 9 October 1992

and in revised form

11 January 1993

Accepted 19 January 1993
There has been no other histopathological study on the mechanisms of large intracranial artery thrombosis. ${ }^{4}$

Conversely, abundant histopathological studies have been performed on coronary artery thrombosis in myocardial infarction, and have documented a rupture of atheroma as a major cause leading to thrombus formation. ${ }^{5-12}$ Though break, ${ }^{28}$ rupture, ${ }^{3-10}$ fissuring $^{581112}$ and cracking ${ }^{8}$ of atherosclerotic plaque of the cerebral or coronary arteries are terms that have appeared in previous reports describing the disruption of the luminal surface of the plaque, we have used the term "rupture of the plaque" in this report.

The necropsied patients died within 28 days after brain infarction due to large intracranial artery thrombosis and we were able to perform detailed histopathological analysis on the mechanisms leading to the thrombus formation.

\section{Subjects and methods}

Among 771 adult brains necropsied at the National Cardiovascular Center between 1979 and 1991, 114 brains had infarcts which had developed within 28 days before death. Of these cases, the intra-arterial thrombi in the circle of Willis and its major branches were histopathologically confirmed in only six cases, after thromboemboli originating from the heart or the carotid arteries and thrombi associated with aneurysms of the cerebral arteries were excluded. Two additional necropsy cases in other hospitals which met the same criteria were also included. We analysed the history of illness, CT scans of the brain, cerebral angiograms and necropsy findings of these eight patients. Angiographic examination of the cerebral arteries was performed on patients $1,2,5$, and 7 after prodromal ischaemic neurological symptoms or brain infarction. The patients, seven men and one woman, were aged 61-77 (mean 66) years. The risk factors of the patients were assessed. All patients were hypertensive, and two had diabetes mellitus and another had hypercholesterolaemia (table 1).

At necropsy, the brains were removed and fixed in $10 \%$ formalin. After fixation, the circle of Willis and its major branches were removed and decalcified in $45 \%$ formic acid 
Table 1 Clinical profiles of eight patients with large intracranial artery thrombosis

\begin{tabular}{|c|c|c|c|c|c|c|c|c|c|}
\hline \multirow{2}{*}{$\begin{array}{l}\text { Patient } \\
\text { number }\end{array}$} & \multirow{2}{*}{$\begin{array}{l}\text { Agel } \\
\text { Sex }\end{array}$} & \multicolumn{3}{|c|}{ Risk factors } & \multirow{2}{*}{$\begin{array}{l}\text { Prodromal } \\
\text { ischaemic symptoms }\end{array}$} & \multirow[b]{2}{*}{ Mode of onset } & \multirow[b]{2}{*}{ Areas of infarct } & \multirow{2}{*}{$\begin{array}{l}\text { Survival } \\
\text { after infarct }\end{array}$} & \multirow[b]{2}{*}{ Causes of death } \\
\hline & & $H T$ & $D M$ & $H C$ & & & & & \\
\hline 1 & $61 / M$ & + & + & - & - & Progressive & R PICA area & 19 days & $\begin{array}{l}\text { Respiratory failure } \\
\text { due to infarction }\end{array}$ \\
\hline 2 & $67 / \mathrm{F}$ & + & - & - & $\begin{array}{l}\text { TIAs ( } 2 \text { times) and } \\
\text { RIND during } \\
\text { the last } 32 \text { days }\end{array}$ & Abrupt & L MCA 2 area & 12 days & $\begin{array}{l}\text { Pulmonary } \\
\text { embolism }\end{array}$ \\
\hline 3 & 77/M & + & - & - & - & Progressive & R MCA 2 area & 17 days & $\begin{array}{l}\text { Bleeding from } \\
\text { stomach cancer }\end{array}$ \\
\hline 4 & $55 / \mathrm{M}$ & + & - & - & - & Progressive & R PICA area & 4 days & $\begin{array}{l}\text { Respiratory failure } \\
\text { due to infarction }\end{array}$ \\
\hline 5 & $66 / M$ & + & + & + & $\begin{array}{l}\text { Repeated TIAs } \\
\text { during the last } 18 \\
\text { days }\end{array}$ & Progressive & L PICA area & 12 days & $\begin{array}{l}\text { Respiratory failure } \\
\text { due to infarction }\end{array}$ \\
\hline 6 & $73 / \mathrm{M}$ & + & - & - & - & Progressive & R ACA 2 area & 17 days & $\begin{array}{l}\text { Intraperitoneal } \\
\text { bleeding }\end{array}$ \\
\hline 7 & $61 / M$ & + & - & - & - & $\begin{array}{l}\text { Insidious } \\
\text { during sleep }\end{array}$ & R MCA 1 area & 8 days & $\begin{array}{l}\text { Brain herniation } \\
\text { due to infarction }\end{array}$ \\
\hline 8 & $68 / M$ & + & - & - & - & $\begin{array}{l}\text { Insidious } \\
\text { during sleep }\end{array}$ & R MCA 2 area & 25 days & $\begin{array}{l}\text { Congestive } \\
\text { heart failure }\end{array}$ \\
\hline
\end{tabular}

HT = hypertension, $\mathrm{DM}=$ diabetes mellitus, $\mathrm{HC}=$ hypercholesterolaemia, $\mathrm{M}=$ male, $\mathrm{F}=$ female, $+=$ present,$-=$ absent, $\mathrm{R}=$ right, $\mathrm{L}=$ left, TIA $=$ transient ischaemic attack, RIND = reversible ischaemic neurological deficit, MCA $1=$ middle cerebral artery trunk, MCA $2=$ cortical branch of middle cerebral artery, ACA 2 = cortical branch of anterior cerebral artery, PICA = posterior inferior cerebellar artery.

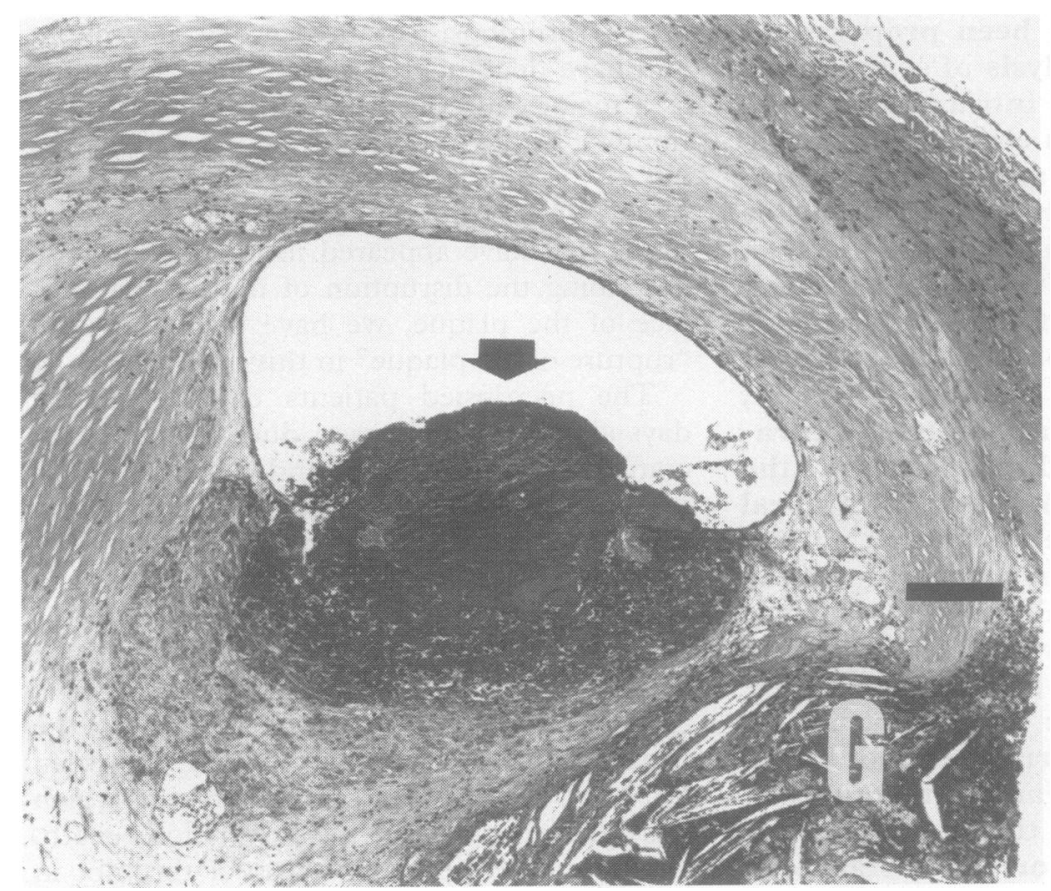

Figure 1 Patient 1. A photomicrograph of a platelet-fibrin thrombus (arrow) formed on plaque ulceration in right vertebral artery $(V A)$. G, gruel of atheroma. Haematoxylin and eosin. Scale bar $=0.2 \mathrm{~mm}$.

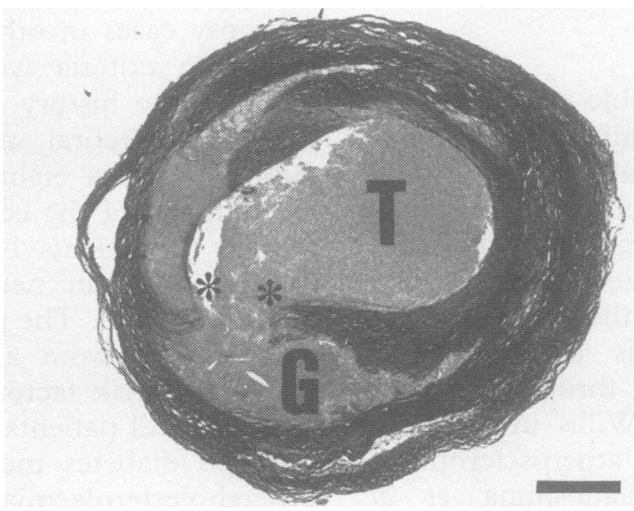

Figure 2 Patient 3. Plaque rupture (between asterisks) and an occlusive thrombus (T) in a cortical branch of right middle cerebral artery (MCA). G, gruel. Elastin van Gieson stain. Scale bar $=0.5 \mathrm{~mm}$. in $10 \%$ sodium citrate solution for two days. Histological examinations were performed at approximately $3 \mathrm{~mm}$ intervals with hematoxylin and eosin staining and other conventional methods. Complete serial sections of the site of thrombotic occlusion or mural thrombus were made when necessary. Special attention was paid to the sources of the emboli to the brain when examining the heart, ascending aorta, and extracranial carotid and vertebral arteries.

The clinical and pathological features of patient 2 have been reported previously. ${ }^{13}$

\section{Results}

Table 1 summarises the clinical profiles of the eight patients with large intracranial artery thrombosis. Anticoagulation or antiplatelet therapy was not given to any patient before or after development of brain infarction. Complete blood count, total protein, fibrinogen, prothrombin time and partial thromboplastin time were normal in all patients. No patient had atrial fibrillation. No case showed specific pathological changes in the heart and extracranial arteries which would be the embolic source to the brain. Patients 2 and 5 showed prodromal ischaemic neurological symptoms in the relevant arterial systems.

Histopathological study of the thrombosed arteries revealed the presence of occlusive thrombi in all eight cases, but the occlusive thrombi in two patients were considered to be thromboemboli dislodged from the mural thrombi observed in the proximal intracranial arteries. In patient 1 , the occlusive thrombi in the right posterior inferior cerebellar artery (PICA) were histologically similar to the mural platelet-fibrin thrombus observed in the right vertebral artery (VA) $1 \mathrm{~cm}$ proximal to the orifice of the occluded PICA. This mural thrombus was localised shortly distal to the severe stenosis and attached to the plaque ulceration where many foam cells infiltrated (fig 1). In patient 2 , the occlusive thromboemboli were observed in the cortical branches of the left middle cerebral artery 


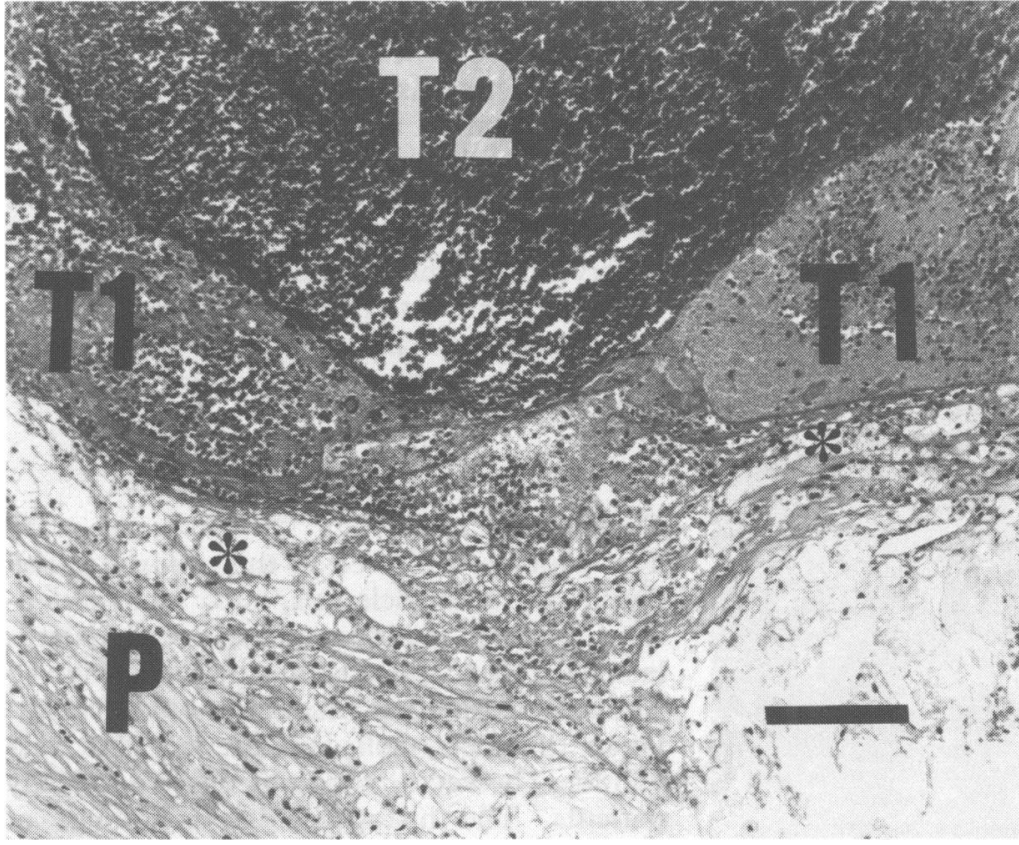

Figure 3 Patient 5. Rupture (between asterisks) of plaque (P) infiltrated with foam cells, and formation of mural platelet-fibrin thrombi (T1) and an occlusive erythrocyte-rich thrombus (T2) in left VA. Haematoxylin and eosin. Scale bar $=0.1 \mathrm{~mm}$.

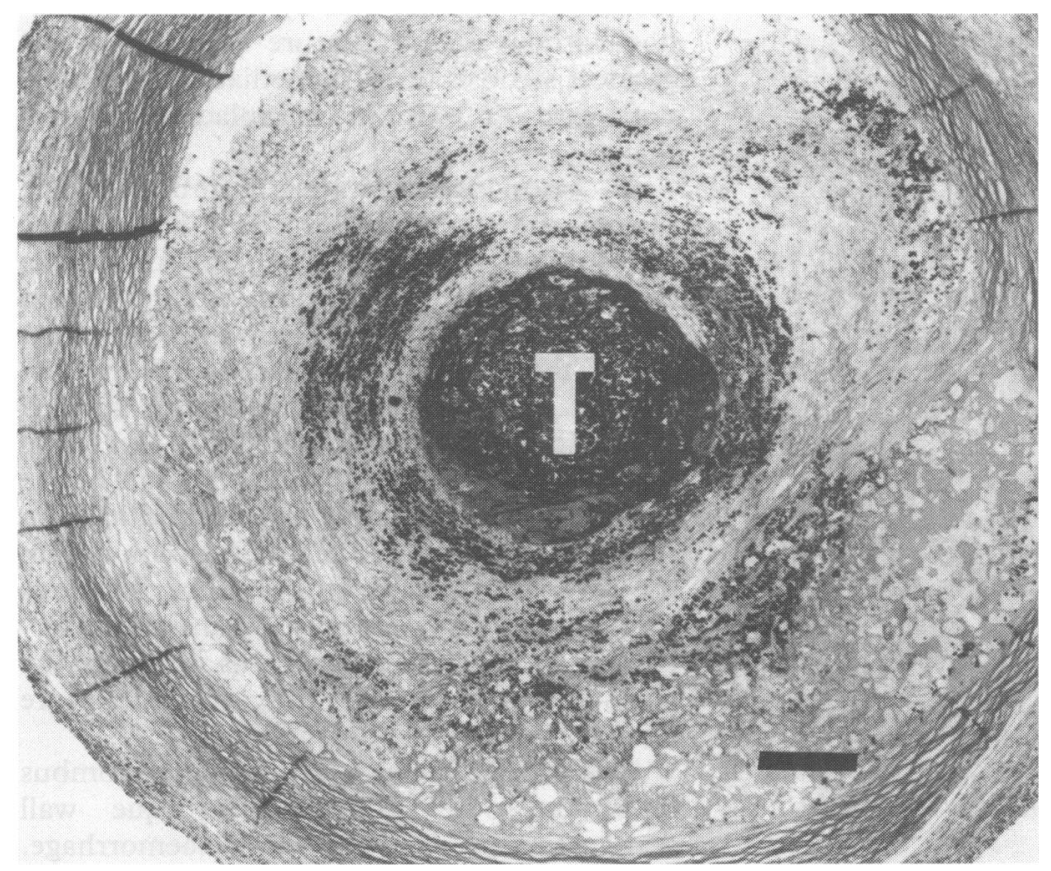

Figure 4 Patient 6. Intraplaque haemorrhage and an occlusive thrombus $(T)$ in a cortical branch of right anterior cerebral artery. Masson's trichrome stain. Scale bar $=0.2 \mathrm{~mm}$.
(MCA), and they were histologically similar to the mural platelet-fibrin thrombus attached to the fibrosed wall of the left MCA trunk immediately distal to the severe stenosis.

The occlusive thrombi observed in the remaining six cases were considered to have formed in situ and were non-embolic. Rupture of atheromatous plaques was observed in patients 3,4 , and 5 . A plateletfibrin thrombus occluded the lumen at the site of the rupture of a fibrous cap over the gruel in the right MCA in patient 3 (fig 2), and in the right VA in patient 4 . The site of the rupture was heavily infiltrated with foam cells in this patient. The plaque rupture was observed at the greatest stenosis and its immediately proximal portion. The left VA of patient 5 showed a platelet-fibrin thrombus attached to the site of plaque rupture and an occlusive erythrocyte-rich thrombus. The site of plaque rupture was heavily infiltrated with foam cells (fig 3). The plaque rupture occurred unrelated to segmental stenosis. Cholesterol crystal emboli were found in the leptomeningeal branches of the bilateral posterior cerebral arteries resulting in multiple small cortical infarcts. The cholesterol crystal emboli probably derived from the plaque rupture in the left VA may have been responsible for the transient ischaemic attacks.

Rupture of the plaque was not observed at the sites of thrombosis in patients 6,7 , and 8 . In patient 6 , intraplaque haemorrhage was found in the fibrosed intima of a cortical branch of the right anterior cerebral artery where a platelet-fibrin thrombus occluded the lumen at the greatest stenosis. The portion of the thrombus in touch with the plaque wall showed advanced organisation compared with the rest of the thrombus (fig 4). Patient 7 demonstrated an occlusive thrombus showing a layered structure of thrombus material of differing age at the greatest stenosis and its immediately distal portion of the right MCA trunk (fig 5). This thrombus may have formed successively by repeated mural deposits causing progressive luminal narrowing. The oldest thrombus was attached to the plaque wall immediately distal to the greatest stenosis, where numerous foam cell infiltrated the innermost area of the plaque. In patient 8 a platelet-fibrin thrombus occluded the lumen of a cortical branch of the right MCA at the greatest stenosis. The portion of the thrombus in touch with the plaque wall showed advanced organisation compared with the rest of the thrombus (figure 6).

Figure 7 illustrates the stenosis of the

Table 2 Histopathological findings of thrombosed large intracranial arteries

\begin{tabular}{llllll}
\hline $\begin{array}{l}\text { Patient } \\
\text { number }\end{array}$ & Thrombosed arteries & Mural or occlusive & Rupture of plaque & $\begin{array}{l}\text { Intraplaque } \\
\text { haemorhage }\end{array}$ & $\begin{array}{l}\text { Greatest } \\
\text { stenosis(\%) }\end{array}$ \\
\hline 1 & R VA & Mural & - & - & 98 \\
2 & L MCA 1 & Mural & - & - & 99 \\
3 & R MCA 2 & Occlusive & + & - & 76 \\
4 & R VA & Occlusive & + & - & 71 \\
5 & L VA & Occlusive & + & + & 97 \\
6 & R ACA 2 & Occlusive & - & - & 95 \\
7 & R MCA 1 & Occlusive & - & - & 93 \\
8 & R MCA 2 & Occlusive & & \\
\hline
\end{tabular}

$\mathrm{R}=$ right, $\mathrm{L}=$ left, $\mathrm{VA}=$ vertebral artery, $\mathrm{MCA} 1$ = middle cerebral artery trunk, MCA 2 = cortical branch of middle cerebral artery, ACA $2=$ cortical branch of anterior cerebral artery, $+=$ present, $=$ absent. Greatest percent stenosis is expressed by percentage of plaque occupying original luminal area. 


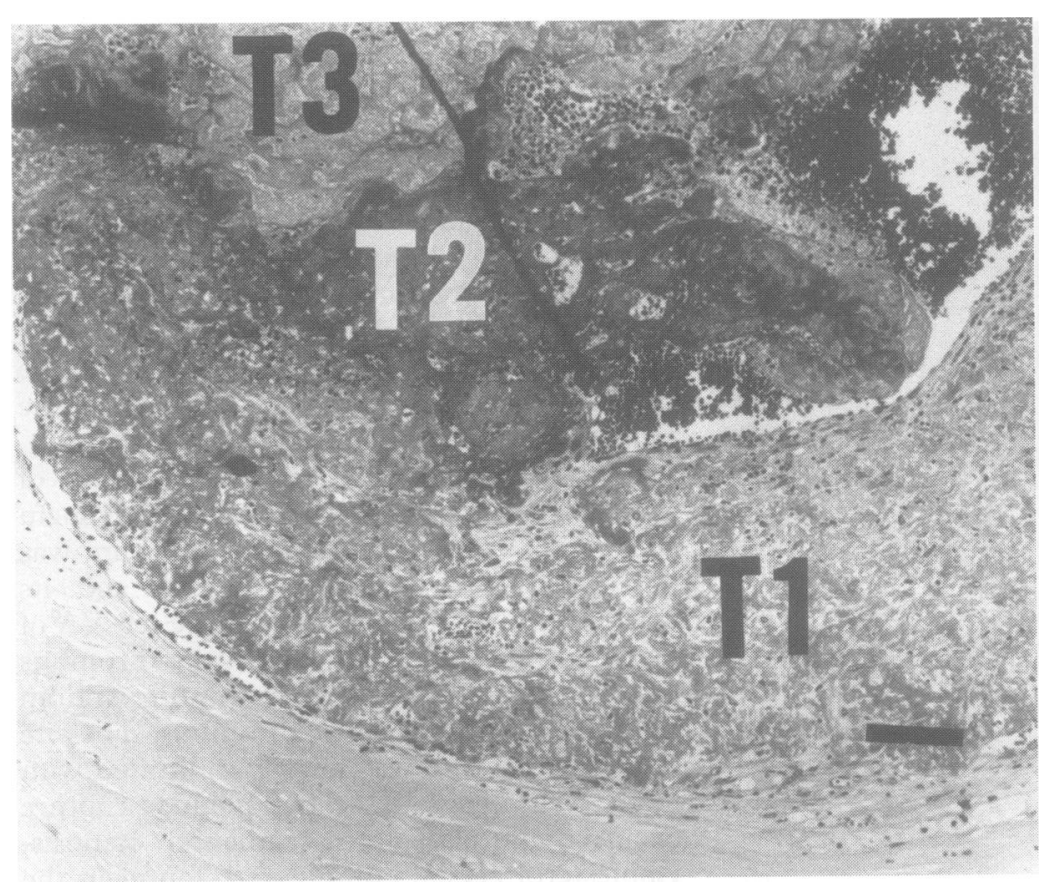

Figure 5 Patient 7. Occlusion of lumen by platelet-fibrin thrombi (T2, T3) developing on an organising thrombus (T1) in right MCA trunk. Foam cells infiltrate innermost area of plaque. Haematoxylin and eosin. Scale bar $=0.1 \mathrm{~mm}$.

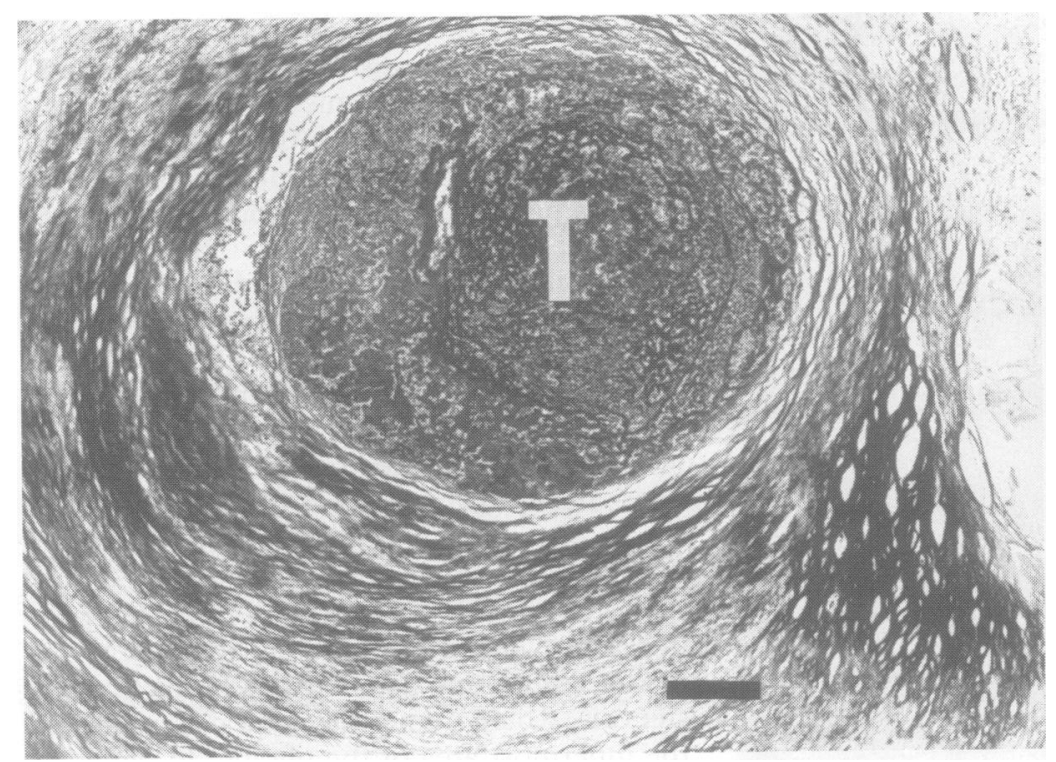

Figure 6 Patient 8. An occlusive thrombus $(T)$ in a cortical branch of right MCA. Masson's trichrome stain. Scale bar $=0.2 \mathrm{~mm}$. observed in only one patient. Thrombosis of the arteries therefore, occurred in relation to segmental stenosis in most cases. The plaque rupture occurred at the greatest stenosis and its immediately proximal portion in two cases and at a site unrelated to segmental stenosis in one. Conversely, thrombus formation observed in the remaining five patients occurred without plaque rupture, at the greatest stenosis in two cases, and at sites immediately distal to the segmental stenosis in three.

\section{Discussion}

The patients subjected to this study had risk factors for atherosclerosis, such as hypertension, diabetes mellitus, and hypercholesterolaemia. Other abnormalities predisposing ${ }^{12}$ to thrombus formation, including blood coagulation disorders, collagen diseases, and vasculitides, however, were not observed in any patients. The histopathological findings of this study may therefore represent the cerebral artery thrombosis that occurs in those with advanced atherosclerosis.

The histopathological characteristics of arterial segments with thrombus formation observed in this study are: 1) rupture of atherosclerotic plaque, and 2) thrombus formation without plaque rupture occurring at the greatest stenosis or its immediately distal portion with or without intraplaque haemorrhage.

In cases demonstrating rupture of the plaque, the essential histological features are exposure of connective tissue and other tissue elements and of clusters of lipid-laden macrophages and extracellular necrotic material of the gruel, to the arterial lumen. The contact of potent platelet activators derived from the vascular tissue elements, and tissue factor, a key protein in the activation of the coagulation cascade, in the gruel and in foam cell-rich regions of the plaque ${ }^{14}$ with blood in the arterial lumen contributed to thrombus formation. This mechanism of thrombus formation in cerebral arteries was described by Constantinides. ${ }^{2}$ In our study, plaque rupture was observed in three of eight cases.

One patient in our study showed thrombus formation over a fibrosed plaque wall demonstrating intraplaque haemorrhage. Intraplaque haemorrhage, not from the backflow of blood through plaque rupture, has been observed at the sites of thrombotic occlusion of the cerebral arteries. ${ }^{13}$ This is mainly due to the rupture of poorly supported intimal small blood vessels, and is a possible trigger mechanism for large intracranial artery thrombosis because it may release thrombogenic substances into the lumen.

In our study, plaque rupture or intraplaque haemorrhage was not essential for the thrombus formation. In four cases, occlusive or mural thrombi developed at the greatest stenosis or its immediately distal portion without plaque rupture or intraplaque haemorrhage. Such thrombus formation has been observed in six of 39 thrombosed segments of 


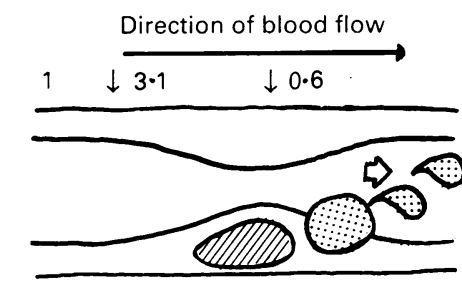

Mural thrombus over plaque ulceration, and its embolisation

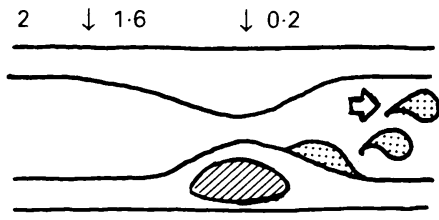

Mural thrombus on fibrosed intima, and its embolisation

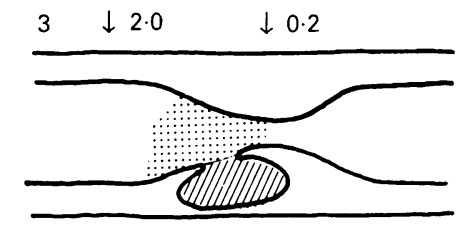

Occlusive thrombus over plaque rupture

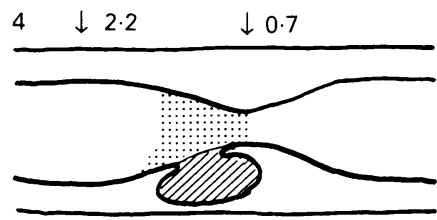

Occlusive thrombus over plaque rupture

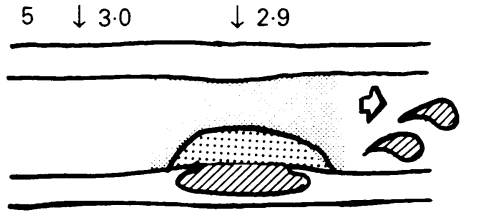

Occlusive thrombus over plaque rupture and embolisation of atheroma content

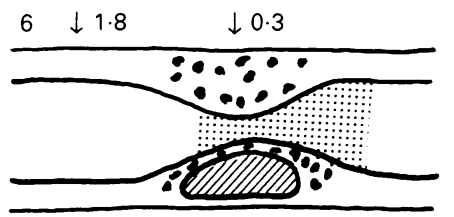

Occlusive thrombus over fibrosed intima with intraplaque haemorrhage

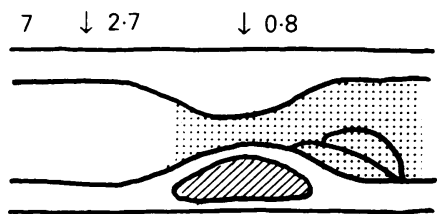

Occlusive thrombus with layered structure over fibrosed intima

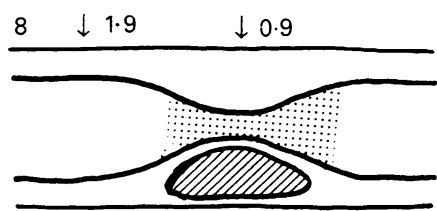

Occlusive thrombus over fibrosed intima

ZIIIA : Gruel of atheroma,

$\because:$ : Intraplaque haemorrhage,

Platelet-fibrin thrombus, : Erythrocyte-rich thrombus

Figure 7 Schematic drawing of distribution and localisation of atherosclerotic changes and thrombi in eight patients. The diameter at the greatest stenosis and 5-10 mm proximal to it are shown in millimeters. to an occlusive one. Thus mural thrombi may grow to form occluding thrombi as shown in patient 7 , and also may give rise to artery-toartery embolism as shown in patients 1 and 2 . Furthermore, advanced organisation of the portion of platelet-fibrin thrombus in touch with plaque wall in patients 6 and 8 suggests that mural thrombi may grow to form occlusive thrombi

Thrombus leading to a myocardial infarction is generally formed at the site of severe stenosis in coronary arteries, ${ }^{910}$ whereas the site of thrombus formation in relation to stenosis in large intracranial arteries has not been previously reported..$^{1-3}$ The present study has confirmed that thrombosis of the large intracranial arteries occurs at the site of greatest stenosis or immediately distal to it in most cases, in the presence or absence of plaque rupture or intraplaque haemorrhage.

These findings create a theoretical background for antiplatelet, anticoagulation and thrombolytic therapy to prevent or treat atherothrombotic stroke, especially in patients with segmental stenosis of the large intracranial arteries demonstrated by cerebral angiography.

We thank Drs Jun Karasawa and Ikuo Ihara for permission to study their necropsy cases.

1 Paterson JC. Capillary rupture with intimal hemorrhage in the causation of cerebral vascular lesions. Arch Pathol the causation of

2 Constantinides P. Pathogenesis of cerebral artery throm bosis in man. Arch Neurol 1967;83:422-8

3 Sadoshima S, Fukushima T, Tanaka K. Cerebral artery thrombosis and intramural hemorrhage. Stroke 1979;10: $411-4$.

4 Capron L. Extra- and intracranial atherosclerosis. In Vinken PJ, Bruyn GW, Klawans HL, Toole JF, eds. Handbook of clinical neurology, vol 53. New York: Elsevier, 1988;91-106.

5 Constantinides P. Plaque fissures in human coronary thrombosis. F Atheroscler Res 1966;6:1-17.

6 Friedman $M$. The coronary thrombus: its origin and fate. Hum Pathol 1971;2:81-128.

7 Horie T, Sekiguchi M, Hirosawa K. Coronary thrombosis in pathogenesis of acute myocardial infarction. Histopathological study of coronary arteries in 108 necropsied cases using serial section. Br Heart $\mathcal{F} 1978 ; 40$ 153-6

8 Davies MJ, Thomas T. The pathological basis and microanatomy of occlusive coronary thrombus formation in human coronary arteries. Philos Trans $R$ Soc Lond [Biology] 1981;296:225-9.

9 Baroldi G. Diseases of the coronary arteries. In: Silver MD, ed. Cardiovascular pathology. New York: Churchil Livingstone 1983:317-91.

10 Falk E. Plaque rupture with severe pre-existing stenosis precipitating coronary thrombosis. Characteristics of coronary atherosclerotic plaques underlying fatal occlucoronary atherosclerotic plaques underlyin

11 Davies MJ. Thomas AC. Plaque fissuring - the cause of acute myocardial infarction, sudden ischaemic death, acute myocardial infarction, sudden ischaemic

12 Davies MJ. Thrombosis in acute myocardial infarction and sudden death. Cardiovasc Clin 1987;18:151-9.

13 Masuda J, Ogata J, Yutani C, et al. Artery-to-artery embolism from a thrombus formed in stenotic middle cerebral artery. Report of an autopsy case. Stroke 1987 18:680-4.

14 Wilcox JN, Smith KM, Schwartz SM, et al. Localization of tissue factor in the normal vessel wall and in the ath erosclerotic plaque. Proc Natl Acad Sci USA 1989;86: 2839-43.

15 Mustard JF, Packham MA, Kinlough-Rathbone RI Platelets, blood flow, and the vessel wall. Circulation 1990;81 (suppl I):I-24-7.

16 Masuda J, Ross R. Atherogenesis during low-level hypercholesterolemia in the nonhuman primate. I. Fatty streak formation. Arteriosclerosis 1990;10:164-77. 